\title{
ACCURACY OF FINE NEEDLE ASPIRATION CYTOLOGY IN DIAGNOSING VARIOUS BREAST LESIONS WITH HISTOPATHOLOGICAL CORRELATION
}

\author{
Susmitha N. S1, Sathyaki D. $C^{2}$
}

${ }^{1}$ Assistant Professor, Department of Pathology, Sri Siddhartha Medical College.

${ }^{2}$ Assistant Professor, Department of ENT, Sri Siddhartha Medical College.

ABSTRACT
BACKGROUND
FNAC has become an important preoperative and screening test for breast masses. The sensitivity and specificity of the
procedure are extremely high when combined with clinical examination and imaging. Main objective is to separate malignant lesions
that require prompt surgical excision from benign ones.

\section{AIMS AND OBJECTIVES}

The present study was undertaken to know the accuracy of FNAC in diagnosing various breast lesions and its histopathological correlation.

\section{MATERIALS AND METHODS}

A prospective study was conducted over duration of 18 months from January 2012 to June 2013. FNACs were performed on 124 breast lesions and correlated with HPE in 45 cases.

\section{RESULTS}

Out of 124 FNACs done, benign breast lesions predominated with 102 cases followed by malignant lesions which were 22 in number. Biopsies were obtained for all the malignant lesions and in only 23 cases for benign lesions. Among 23 benign cases, excisional biopsies obtained all correlated with the cytological diagnosis. Among the 22 malignant breast lesions, 2 were reported as benign on FNAC (False negative in disease). Overall Sensitivity, Specificity and false negative percentage values were $95.55 \%, 100 \%$ and $4.44 \%$ respectively.

\section{CONCLUSION}

FNAC of the breast is a simple, cost effective, accurate, quick and relatively less painful procedure. Our study concluded that an occasional false negative case makes it mandatory to biopsy and subject it for histopathological examination before mastectomy in cases where clinical and cytological diagnosis do not concur and also in cases where the diagnosis of malignancy on cytology is suspicious.

\section{KEYWORDS}

FNAC, Breast Lesions, Biopsy.

HOW TO CITE THIS ARTICLE: Susmitha NS, Sathyaki DC. Accuracy of fine needle aspiration cytology in diagnosing various breast lesions with histopathological correlation. J. Evolution Med. Dent. Sci. 2016;5(75):5564-5567, DOI: 10.14260/jemds/2016/1257

\section{INTRODUCTION}

Breast disease is the most common disease in females. In addition, carcinoma of the breast ranks first among malignant tumours affecting females in many parts of the world.[1] Increasing awareness of breast cancer has stimulated profound interest in benign breast lesions, since certain epithelial lesions have been associated with malignant transformation.[2]

FNAC has been used extensively over the past 25 years. It plays a major role as an important preoperative assessment procedure along with clinical correlation and imaging, which are referred to as the Triple test.[3] Limitation of an FNAC is its inability to separate in situ and invasive carcinoma. ${ }^{[4]}$

Financial or Other, Competing Interest: None.

Submission 11-08-2016, Peer Review 02-09-2016,

Acceptance 10-09-2016, Published 19-09-2016.

Corresponding Author:

Dr. Susmitha N. S

Assistant Professor

Department of Pathology,

Sri Siddhartha Medical College, Tumkur.

E-mail: sush_susmitha2000@yahoo.co.in

DOI: $10.14260 /$ jemds/2016/1257

\section{(c) (i) $(9)$}

However, FNAC has its own benefits, being a quick and cheap procedure featuring: a short turnover time; high diagnostic accuracy; less patient discomfort; provision of multiple sampling from multiple areas, provision of ancillary tests and curative relief in some cases, as in case of aspiration of cyst. $(5,6)$

The present study aims at performing FNAC followed by histopathological correlation in order to find out the role and accuracy of FNAC in diagnosing various breast lesions.

\section{MATERIALS AND METHODS}

Sources of Data

All FNACs of breast done on patients referred to us and also biopsies received at the Department of Pathology, Shri Adichunchanagiri Institute of Medical Sciences, B. G. Nagar and other peripheral hospitals from January 2012 to June 2013, i.e. 18 months were included for the present study.

\section{Method of Collection of Data}

After a detailed clinical history and examination all the clinical findings along with the results of the investigations done were recorded in detailed proforma. 


\section{Sample Size}

A total of 124 patients with breast lumps were subjected for FNAC examination and also a histopathological study after obtaining approval from the Institutional Ethics Committee.

The FNAC procedure was explained to the patient and oral consent taken. FNACs were performed under aseptic precautions and subsequently the smears were stained by Haematoxylin and Eosin, Papanicolaou stains. The air dried smears were stained with Giemsa stain.

The tissue biopsies obtained were processed and the slides stained with $\mathrm{H}$ and $\mathrm{E}$ and wherever necessary with special stains like Periodic Acid-Schiff, Mucicarmine, etc.

\section{Inclusion Criteria}

All cases with breast lesions were included for FNAC study, and only those cases for histopathological examination which were suggestive of malignancy on FNAC study.

\section{Exclusion Criteria}

Cases of those breast lumps were excluded from histopathological study, where the FNAC study pointed towards only benign lesions and where there was absolutely no ambiguity regarding FNAC and clinical diagnosis.

\section{RESULTS}

In total, 124 breast aspirations were studied. The observations of the study were as follows.

The age of the patients ranged from 6 to 80 years. There were 122 female patients and 2 male patients. Out of 124 aspirations done, benign breast lesions predominated with 102 cases followed by malignant lesions, which were 22 in number (Table 1).

\begin{tabular}{|c|c|}
\hline Breast Lesions & Number of Cases \\
\hline Benign Breast Lesions & 102 \\
\hline Inflammatory Lesions & 26 \\
\hline Non-Neoplastic Lesions & 28 \\
\hline Benign Tumours & 48 \\
\hline Malignant Breast Lesions & 22 \\
\hline \multicolumn{2}{|c|}{ Total } \\
\hline Table 1: Showing Final Diagnosis of Breast Lesions \\
\hline
\end{tabular}

Among benign breast lesions, fibroadenoma was the most common with 40 cases. Among the malignant lesions, Infiltrating Ductal Carcinoma had highest incidence rates with 18 numbers of cases (Table 2).

Fibroadenoma is probably the commonest breast lesion for which FNAC is performed.(7)

\begin{tabular}{|c|c|c|}
\hline $\begin{array}{c}\text { Benign Breast } \\
\text { Lesions }\end{array}$ & $\mathbf{1 0 2}$ \\
\hline \multirow{3}{*}{$\begin{array}{c}\text { Inflammatory and } \\
\text { Related Lesions }\end{array}$} & Acute Mastitis & 12 \\
\cline { 2 - 3 } & Acute on Chronic Mastitis & 3 \\
\cline { 2 - 3 } & Breast Abscess & 9 \\
\cline { 2 - 3 } & Galactocoele & 2 \\
\hline \multirow{3}{*}{ Non-Neoplastic } & Fibrocystic Change & 26 \\
\cline { 2 - 3 } & Gynaecomastia & 1 \\
\cline { 2 - 3 } & Epithelial Hyperplasia & 1 \\
\hline \multirow{4}{*}{ Benign Tumours } & Fibroadenoma & 42 \\
\cline { 2 - 3 } & Lipoma & 3 \\
\cline { 2 - 3 } & Adenomyoepithelioma & 1 \\
\cline { 2 - 3 } & Haemangioma & 1 \\
\hline
\end{tabular}

\begin{tabular}{|c|c|c|}
\hline \multirow{4}{*}{$\begin{array}{c}\text { Malignant Breast } \\
\text { Tumours }\end{array}$} & Spindle Cell Lesion & 1 \\
\cline { 2 - 3 } & $\begin{array}{c}\text { Infiltrating Ductal } \\
\text { Carcinoma, NOS }\end{array}$ & 15 \\
\cline { 2 - 3 } & IDC, Mucinous Type & 1 \\
\cline { 2 - 3 } & IDC, Medullary Type & 1 \\
\cline { 2 - 3 } & IDC, Papillary Type & 1 \\
\cline { 2 - 3 } & $\begin{array}{c}\text { Invasive Lobular } \\
\text { Carcinoma }\end{array}$ & 3 \\
\cline { 2 - 3 } & Malignant Phyllodes & 1 \\
\hline \multicolumn{2}{|c|}{} & $\mathbf{1 2 4}$ \\
\hline \multicolumn{2}{|c|}{ Table 2: Showing Incidence of Breast Lesions } \\
\hline
\end{tabular}

\section{Statistical Analysis}

Cytological diagnosis was correlated with histopathology wherever possible and efficacy of FNAC was calculated; 45 cases out of 124 had a corresponding histological diagnosis. With this confirmation an overall sensitivity, negative predictive value and false negative indices were calculated.

Biopsies were obtained for all the malignant lesions and in only 23 cases for benign lesions. Among 23 benign cases, excisional biopsies obtained all correlated with the cytological diagnosis. Among the 22 malignant breast lesions, 2 were reported as benign on FNAC (False negative in disease).

One case of Lobular carcinoma showed cytohistopathological discordance. The case was diagnosed as sclerosing adenosis on FNAC, which was clinically suspected of carcinoma. The MRM specimen was received and a final diagnosis of ILC was made [Figure 1(a), (b)].

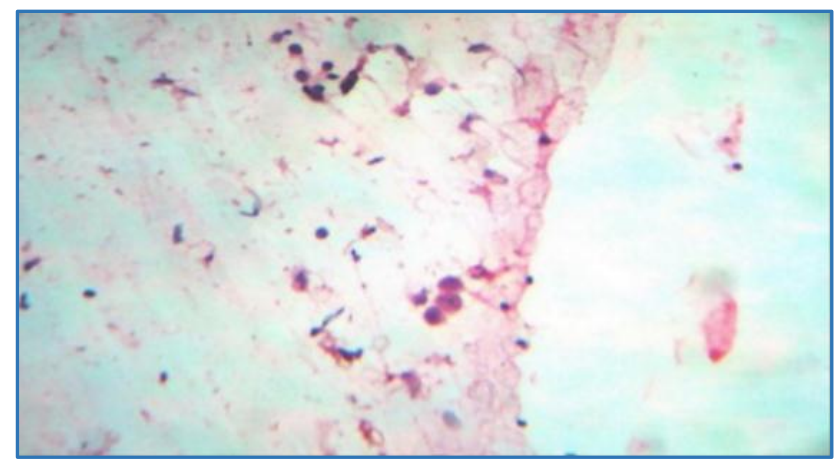

Fig. 1(a): Cytology: Smear showing Monomorphic Cells in Singles 10x, $\mathrm{H} \& \mathrm{E}$

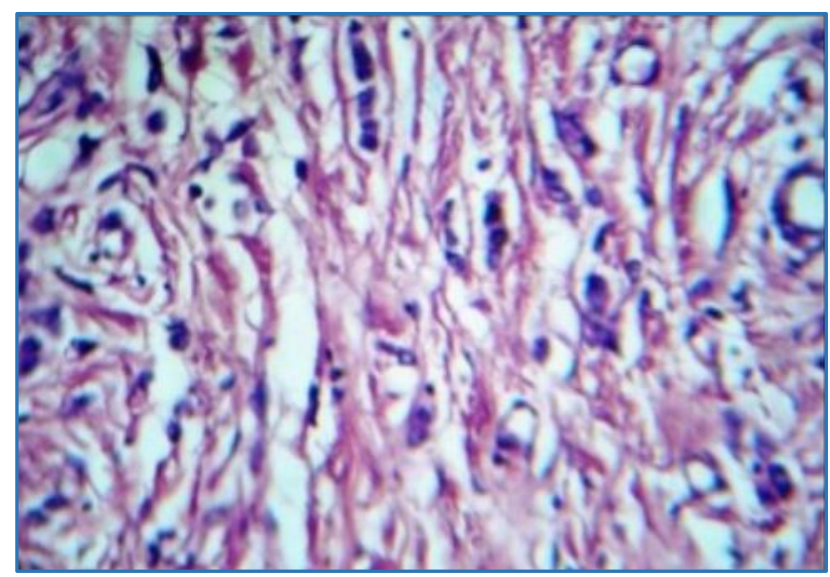

Fig. 1(b): HP: Indian File Pattern of Growth. Individual Cells are Mildly Pleomorphic with Hyperchromatic Round Nuclei. 40x, $\mathrm{H} \& \mathrm{E}$ 
Another case of Malignant Phyllodes showed cytohistopathological discordance. Clinically, a diagnosis of Phyllodes tumour was made. On FNAC, diagnosis of Phyllodes tumour with epithelial hyperplasia was made. MRM specimen showed histopathological features of Malignant Phyllodes tumour [Figure 2 (a), (b), (c)].

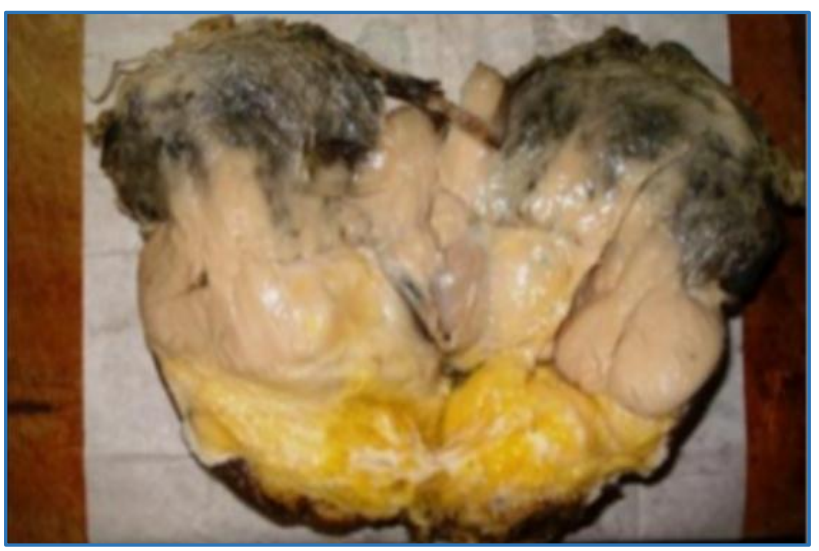

Fig. 2(a): Gross: Large Solid Grey White Tumour with Extensive Areas of Haemorrhagic Infarct

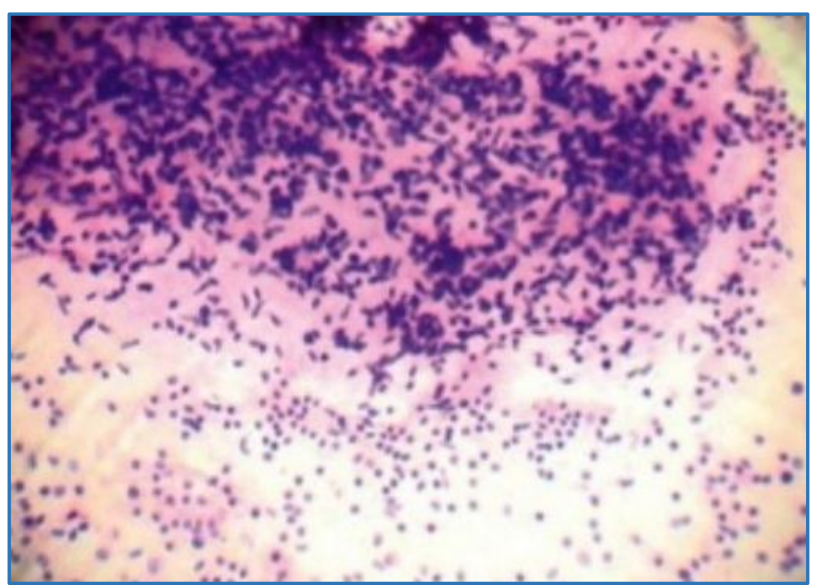

Fig. 2(b): Cytology: Smear showing Large Stromal Fragments. 10x, $\mathrm{H} \& \mathrm{E}$

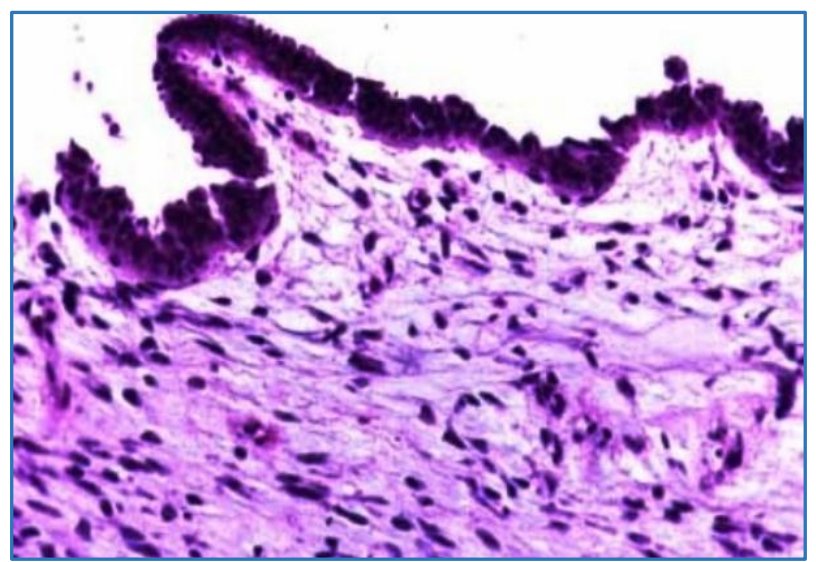

Fig. 2(c): HP: Section showing Leaf-Like Proliferation of the Stromal Tissue showing Hypercellularity and Atypia of the Lining Epithelium. 40x, $\mathrm{H} \& \mathrm{E}$

Therefore, in 2 out of 45 cases the diagnosis at cytology was not in keeping with histology.

True Positives $=43$.

False Negatives $=02$.

\begin{tabular}{|c|c|c|}
\hline Value & Formula & Percentage \\
\hline Sensitivity & $\mathrm{TP}(43) / \mathrm{TP}(43)+\mathrm{FN}(2) \mathrm{X} 100$ & $95.55 \%$ \\
\hline $\begin{array}{c}\text { False } \\
\text { Negative } \\
\text { Percentage }\end{array}$ & $\mathrm{FN}(2) / \mathrm{TP}(43)+\mathrm{FN}(2) \mathrm{X} 100$ & $4.44 \%$ \\
\hline \multicolumn{3}{|c|}{ Table 3: Overall Statistical Analysis } \\
\hline
\end{tabular}

\section{DISCUSSION}

FNAC of breast masses is widely accepted as a reliable diagnostic tool with high sensitivity and specificity. Frable used 22 gauge needles, 1.5 inches length for aspirating various lesions and felt that careful clinical examination of the breast mass to confirm its presence and consistency are important for the needle aspiration and suggested that there is a need to explain the aspiration procedure to the patient. ${ }^{[8]}$

In the present study, 124 breast lumps detected at clinical examination were subjected for cytohistopathological examination. The age of the patients with lump in the breast ranged from 6 to 80 years with majority in the 21-40 years' age group. In majority of the patients, i.e. 60 cases of left breast was involved and in 55 cases the right breast and in 9 cases both the breasts were involved. Male-to-female ratio was 122 cases in females and 2 cases of males, i.e. 98.4:1.6.

The present study documented 102 cases of benign breast lesions constituting $82.25 \%$ and 22 cases of malignant lesions constituting $17.74 \%$. Fibroadenoma was the most common diagnosis observed in $41.2 \%$ of cases followed by fibrocystic change in $27 \%$.

Among the 102 benign breast lesions, excisional biopsies were obtained for 23 cases. All the cases showed cytohistopathological correlation. Thus, accounting for a $100 \%$ sensitivity and specificity.

Of the 22 cases of malignant tumours majority were in the age group of 41-60 years, all were female patients. The most common type was IDC seen in 18 cases $(81.8 \%)$. The other malignant tumours included ILC in 3 cases $(13.6 \%)$ and malignant Phyllodes tumour in 1 case (4.5\%).

Among 22 malignant breast tumours, there were 2 cases of false negative diagnosis. However, there was no false positive diagnosis. The cytohistological diagnosis concordance was seen in 20 cases.

In the case which was cytologically diagnosed as Sclerosing adenosis but turned out to be ILC on HPE, the aspiration was gritty and yielded scanty haemorrhagic material. Smears showed moderate cellularity, composed of tumour cells in sheets, small clusters and occasional in singles. Individual cells showed mild pleomorphism. Grossly, the tumour was solid, grey-white with infiltrating margins and HPE showed malignant cells in Indian file, singles and in vague concentric pattern. Scanty cellularity and cells in clusters on FNAC led to a false negative diagnosis.

Numerous studies had concluded lobular carcinoma to be the most commonly misdiagnosed variety of breast malignancy.(9,10) Cytology smears show variable cellularity with a dispersed population of monomorphic cells, mild nuclear atypia and bland chromatin. It has been documented that the cellularity of an invasive lobular carcinoma in cytology smears correlates with histopathological architectural pattern rather than with the original histopathological cellularity.(11)

In the case which was cytologically diagnosed as Phyllodes tumour with epithelial hyperplasia, but turned out to be Malignant phyllodes on HPE, the aspiration was blood mixed 
grey-white material. Smears showed moderate cellularity comprising of epithelial cells in cohesive sheets, in 3D clusters along with stromal fragments. Grossly, the tumour was huge, grey-white, lobulated with cleft like areas. HPE showed hypercellularity of stromal component in leaf-like pattern along with epithelial component. Atypical mitosis $>10 / 10 \mathrm{HPF}$ was noted.

Phyllodes tumour constitutes an important grey zone lesion. Cytology aspirates cannot also properly distinguish between benign, borderline and malignant phyllodes tumour. Nuclear pleomorphism and number of mitosis increase progressively from a borderline to malignant phyllodes. These features are subjective and difficult to assess on cytology smears.(12)

Comparison of sensitivity, specificity, positive predictive value and negative predictive value with other published studies is shown in the table below [Table 4].

\begin{tabular}{|c|c|c|c|}
\hline $\begin{array}{c}\text { Statistical } \\
\text { Parameters }\end{array}$ & $\begin{array}{c}\text { Ishita } \\
\text { et al }\end{array}$ & $\begin{array}{c}\text { Sushma } \\
\text { et al }\end{array}$ & $\begin{array}{c}\text { Present } \\
\text { Study }\end{array}$ \\
\hline Sensitivity & 93.10 & 100.00 & $95.55 \%$ \\
\hline Specificity & 97.06 & 88.50 & $100.00 \%$ \\
\hline $\begin{array}{c}\text { Predictive Value of } \\
\text { Positive Result }\end{array}$ & 96.43 & 84.00 & - \\
\hline \multicolumn{3}{|c|}{ Table 4: Showing Comparison of Statistical } \\
Parameters with Other Studies \\
\hline
\end{tabular}

Ishita performed 125 FNAs of breast over a period of 1 year. Of these, 60 cases were followed up by histopathological confirmation. Diagnostic accuracy of this series was assessed. The sensitivity of the FNA procedure was $93.10 \%$, specificity $97.06 \%$ with a positive predictive value $96.43 \% .(13)$

Sushma in their study of 334 breast aspirations over a period of 2 years with histopathological confirmation documented $100 \%$ sensitivity, $88.5 \%$ specificity and the predictive value of a positive result of $84 \%{ }^{(14)}$

\section{CONCLUSION}

Any lump in the breast however benign it may appear on clinical examination has to be subjected for pathological examination to detect any malignant change at the earliest. In this context, FNAC is the most preferred method as it is simple, safe, rapid and reliable initial outpatient procedure. However, an occasional false negative case makes it mandatory to biopsy and subject it for histopathological examination before mastectomy in cases where clinical and cytological diagnosis do not concur and also in cases where the diagnosis of malignancy on cytological examination is suspicious.

\section{REFERENCES}

1. Man N, Salahuddin O, Azhar MF, et al. Breast diseases: spectrum in Wah Cantt, POF hospital experience. Professional Med J 2010;17(3):366-72.

2. Ochicha O, Edino ST, Mohammed AZ, et al. Benign breast lesions in Kano. Nigerian J Surg Research 2002;4(1-2):15.

3. Muddegowda PH, lingegowda JB, Kurpad R, et al. The value of systematic pattern analysis in FNAC of breast lesions: 225 cases with cytohistological correlation. Journal of Cytology 2011;28((1):13-9.

4. Bibbo M, Wilbur DC. Comprehensive cytopathology. $3^{\text {rd }}$ edn. Philadelphia: Elsevier Saunders 2008:713-5(a), 72575(b).

5. Rosa M, Mohammadi A, Masood S. The value of FNAB in the diagnosis and prognostic assessment of palpable breast lesions. Diagn Cytopathol 2012;40(1):26-34.

6. Abdel-Hadi M, Abdel-Hamid GF, Abdel-Razek N, et al. Should FNAC be the first choice diagnostic modality for assessment of all nonpalpable breast lesions? The experience of a breast cancer screening center in Alexandria, Egypt. Diagn Cytopathol 2010;38(12):880-9.

7. Simsir A, Cangiarella J. Challenging braest lesions: pitfalls and limitations of FNA and the role of core biopsy in specific lesions. Diagn Cytopathol 2012;40(3):262-72.

8. Frable WJ. Needle aspiration biopsy: past, present and future. Hum Pathol 1989;20(6):504-17.

9. Rajesh L, Dey P, Joshi K. FNAC of lobular breast carcinoma. Comparison with other breast lesions. Acta Cytol 2003;47(2):177-82.

10. Joshi A, Kumar N, Verma K. Diagnostic challenge of lobular carcinoma on aspiration cytology. Diagn Cytopathol 1998;18(3):179-83.

11. Abdulla M, Hombal S, al-Juwaiser A, et al. Cellularity of lobular carcinoma and its relationship to false negative FNA results. Acta Cytol 2000;44(4):625-32.

12. Shabb NS. Phyllodes tumor. Fine needle aspiration cytology of eight cases. Acta Cytol 1997;41(2):321-6.

13. Ishita P, Singh PK. Cytomorphologic study of palpable breast lesions and histopathologic correlation. J Cytol 2003;20:129-32.

14. Sushma Y, Tanikella R, Prabhala S, et al. Histopathological and cytological correlation of tumors of breast. Medical Journal of Dr. D. Y. Patil University 2014;7(3):326-31. 